\title{
FRANÇOIS LASSERRE, Corneille entre les lignes
}

\section{Monica Pavesio}

\section{(2) OpenEdition \\ Journals}

\section{Edizione digitale}

URL: https://journals.openedition.org/studifrancesi/31648

DOI: 10.4000/studifrancesi.31648

ISSN: 2421-5856

\section{Editore}

Rosenberg \& Sellier

\section{Edizione cartacea}

Data di pubblicazione: 1 août 2020

Paginazione: 399-400

ISSN: 0039-2944

\section{Notizia bibliografica digitale}

Monica Pavesio, «françols Lasserre, Corneille entre les lignes», Studi Francesi [Online], 191 (LXIV | II) | 2020, online dal 01 septembre 2020, consultato il 18 septembre 2021. URL: http://

journals.openedition.org/studifrancesi/31648 ; DOI: https://doi.org/10.4000/studifrancesi.31648

Questo documento è stato generato automaticamente il 18 septembre 2021.

\section{(2) $\odot \Theta \Theta$}

Studi Francesi è distribuita con Licenza Creative Commons Attribuzione - Non commerciale - Non opere derivate 4.0 Internazionale. 


\title{
FRANÇOIS LASSERRE, Corneille entre les lignes
}

\author{
Monica Pavesio
}

\section{NOTIZIA}

FRANÇOIS LASSERRE, Corneille entre les lignes, Paris, L'Harmattan, 2019, $188 \mathrm{pp}$.

1 Il volume contiene tre studi sul teatro di Pierre Corneille: Corneille, critique de Shakespeare, pp. 9-80; Alidor ou l'Indifférent, déguisement pastoral, pp. 81-123; Corneille défiguré, pp. 125-188. Nel primo saggio, F. Lasserre si interroga sui rapporti tra Corneille e Shakespeare, partendo dal presupposto che il drammaturgo francese non può aver ignorato completamente l'opera del suo predecessore inglese. Passa in rassegna le opere di Corneille alla ricerca di tracce testuali shakespeariane, classificandole in "indices ponctuels" e in "reminiscences". I primi, come si sa, e come ammette lo stesso autore, sono rarissimi, le seconde non sono sempre facilmente collegabili solo alle pièces del drammaturgo inglese. Ci sono poi alcune "rencontres" tra opere dei due drammaturghi, definite da Lasserre di più grande portata. Queste "rencontres", che provano la conoscenza da parte di Corneille di opere come Riccardo III, Antonio e Cleopatra, Sogno di una notte di mezza estate, Romeo e Giulietta, mettono in luce, secondo lo studioso, la volontà del drammaturgo francese di rileggere il teatro shakespeariano, distanziandosi da esso in maniera profonda.

2 Il secondo studio è dedicato ad una pastorale anonima, Alidor ou l'Indifférent, che Lasserre ha pubblicato nel 2001, presso l'editore dell'Orso. In questa Nouvelle présentation d'“Alidor" et de son attribution à Corneille, lo studioso, dopo un lungo excursus sulla drammaturgia corneliana e sull'utilizzo del genere della tragicommedia, presenta ed analizza la comédie pastorale, mettendo in luce gli indizi che lo portano a pensare che possa essere stata scritta da Corneille.

3 Nell'ultimo saggio, l'autore ripercorre, in ordine sparso, alcune grandi idee preconcette sulla vita e sull'opera di Corneille, spesso accusato di essere orgoglioso, troppo legato al 
denaro e al potere, di avere intenzioni moraleggianti, di non essere in grado di dipingere l'amore e di non essere un autore tragico. Lasserre confuta una ad una queste affermazioni erronee, partendo da quella relativa alle sue pièces scritte durante la giovinezza, considerate troppo a lungo come una sorta di esercizio preliminare alla composizione delle opere successive, ritenute da sempre migliori. Si sofferma poi sull'Excuse à Ariste, per molti critici determinante nella Querelle del Cid, per Lasserre solo un pretesto, perché scritta probabilmente nel 1634. Le altre idee preconcette sull'opera drammaturgica di Corneille sono scaturite, secondo Lasserre, dal prestigio di Racine e dalla comparazione tra i due, nata alla fine del XvII secolo, e poi sviluppatasi nei secoli a venire, e dalla supremazia del secondo sul primo. Corneille è diventato così il drammaturgo che non sapeva dipingere l'amore e che non capiva la nozione di tragico, e le sue opere della maturità, vista la supremazia di Racine, sono state completamente dimenticate, come quelle giovanili.

4 Se alcune delle affermazioni erronee sulla vita e sull'opera del drammaturgo continuano ad avere un certo seguito, bisogna ricordare che, fortunatamente, grazie anche alla pubblicazione nei Classiques Garnier del teatro completo di Corneille, si sta assistendo ad una riscoperta ed alla valorizzazione delle opere del drammaturgo troppo a lungo dimenticate. 